\title{
Papillary Carcinoma
}

National Cancer Institute

\section{Source}

National Cancer Institute. Papillary Carcinoma. NCI Thesaurus. Code C2927.

A malignant epithelial neoplasm characterized by a papillary growth pattern. A papillary carcinoma may be composed of glandular cells (papillary adenocarcinoma), squamous cells (papillary squamous cell carcinoma), or transitional cells (papillary transitional cell carcinoma). Bladder carcinoma is a representative example of papillary transitional cell carcinoma. 